\title{
Smokeless tobacco use, tooth loss and oral health issues among adults in Cameroon
}

\author{
Agbor MA ${ }^{1}, *$ Azodo $\mathrm{CC}^{2}$, Tefouet $\mathrm{TSM}^{3}$
}

1. Department of Community Dentistry, University of the Western Cape, Cape Town, South Africa

2. Department of Periodontics, University of Benin, Benin City, Nigeria

3. Dental Department, New Baptist health Centre, Bamenda, Cameroon

\begin{abstract}
Background: Tobacco use in smokeless and smoked forms is preventable cause of mortality and morbidity worldwide. Objective: To determine the prevalence of smokeless tobacco use and the association with tooth loss and oral health problems among adults in Cameroon.

Methods: Adults dwelling in the Fokoue area of West Region of Cameroon were studied.

Results: Out of the 226 participants studied, 119 of them reported smokeless tobacco use giving a prevalence of $52.7 \%$ with majority-74 (62.2\%) chewing it. Three-quarters (77.3\%) of the respondents use it more than than thrice-daily and more than half of them respondents have been using it for 6-10 years. The smokeless tobacco users were more of those aged 5059 years, females, farmers, those with less than post-primary education, non alcohol consumers and those that have not received previous dental care than smokeless tobacco users. However, it was only age $(p=0.006)$ and educational attainment $(p=0.009)$ that were significantly associated with smokeless tobacco use. Smokeless tobacco user were more likely to have poor oral hygiene, dental caries, gingival recession, leukoplakia, erythroplakia, abnormal growth, tooth wear lesion, experienced tooth loss and edentulousnss than non smokeless tobacco users. However, the significantly associated lesions with smokeless tobacco use were tooth loss $(\mathrm{p}=0.008)$, edentulousness $(\mathrm{p}=0.016)$, gingival recession $(\mathrm{p}=0.006)$ and leukoplakia $(\mathrm{p}=0.001)$. Conclusion: The prevalence of smokeless tobacco use was high among adults in Cameroon and it was associated with more likelihood of oral health problems. There is therefore a need for health education on the health consequences of the smokeless tobacco use with demonstrations by the dentist.
\end{abstract}

Key words: Smokeless tobacco, tooth loss, mucosal problems, adults

African Health Sciences 2013; 13(3): 785 - 790 http:/ /dx.doi.org/10.4314/ahs.v13i3.38

\section{Introduction}

Tobacco use in smokeless and smoked forms is preventable cause of mortality and morbidity worldwide. ${ }^{1}$ It constitutes about $90 \%$ of all drugcaused deaths ${ }^{2}$ and stand out as one of the most significant causes of health inequalities. ${ }^{3}$ Addiction to tobacco is a global epidemic, increasingly ravaging countries and regions with lowered capacity to manage the attendant disability, disease, lost productivity and death. ${ }^{4}$

Tobacco use exacerbates poverty and hindering economic development by leaving families

\author{
*Corresponding author: \\ Dr. Clement C Azodo \\ Department of Periodontics \\ Prof Ejide Dental Complex \\ University of Benin Teaching Hospital \\ P.M.B. 1111 Ugbowo \\ Benin City, Edo State \\ Nigeria \\ Phone: 08034051699 \\ Email: clementazodo@yahoo.com
}

African Health Sciences Vol 13 Issue 3 September 2013 with less money to spend on such basic items as food, education and health care. More than $10 \%$ of total household expenditure in the poorest households in some low- and middle-income countries is spent on tobacco. ${ }^{5}$ The decreased productivity among tobacco users due to increased sickness, associated premature death deprives families of their breadwinners and the nations of a healthy workforce and equally is devastating high public health cost of treating tobacco-caused diseases emphasis the economic implication of this epidemic. ${ }^{5}$ Although, tobacco originated from America, the long history tobacco use in many parts of Africa has resulted in the use being infused and ingrained into their culture. ${ }^{6}$ This is confirmed by request for smoked and smokeless tobacco among other items by young adults and elderly respectively as part of bethoral process in many parts of Africa. In South Africa, smokeless tobacco in form of snuff was reported to have important functions and to be socially acceptable among adults mainly for ceremonial and medicinal use and to a lesser degree for relaxation and pleasure. ${ }^{7}$ 
Smokeless tobacco use has been used since the ancient times but the ban on cigarette smoking in public buildings and avoidance of secondhand smoke effect has resulted in increasing use in modern times. As far back as 1986, the advisory committee to the Surgeon General concluded that the use of smokeless tobacco is not a safe substitute for smoking cigarettes. This is based on the fact that smokeless tobacco consumption causes a number of cancer and non cancerous health problems. ${ }^{8}$ In addition, tobacco absorption through the lining of the mouth results in nicotine addiction and dependence.

Several studies on tobacco use were mainly on cigarette smoking with only a few studies on smokeless tobacco use and these studies are even fewer in developing countries. ${ }^{7,9}$ It was detected that tobacco use was commoner in rural area especially in developing countries from literature review. ${ }^{10,11}$ The smokeless tobacco use by snuff and chewing implies that the local effect in the oral cavity may be dominant. The lacking of information about tobacco use in Cameroon in English literature necessitated this study in Fokoue in the West Province of Cameroon.

The objective of the study was to determine the prevalence and the association of smokeless tobacco use with oral health problems among adults in Cameroon.

\section{Methods}

The study was conducted in Fokoue Sub division found in the Menoua Division in the West Province of Cameroon. It is situated at $15 \mathrm{~km}$ from Dschang the divisional headquarters of Menoua division and $60 \mathrm{~km}$ from Bafoussam the West regional capital. It is located between latitudes $5^{\circ} 20^{\prime}$ and $5^{\circ} 22^{\prime}$ North and longitudes $5^{\circ} 10^{\prime}$ and $5^{\circ} 15^{\prime}$ East. The average altitude, temperature and rainfall are 1400 meters, $20.26^{\circ} \mathrm{C}$ and $1853.8 \mathrm{~mm}$ respectively. The inhabitants of this bamboutos highland which about $2350 \mathrm{~m}$ above sea level and the land mass of about $273 \mathrm{Km}^{2}$ are fishermen and farmers.

After obtainingethical approval from the Ministry of Higher Education and Scientific Research, this cross-sectional survey among middle aged adults and elderly was conducted between December, 2010 and April, 2011. The inclusion criteria were residence in Fokoue for more than 5 years and expressed willing to participate. Two hundred and twenty-six participants were randomly selected from the population in meetings and market places. The chief of the village was informed about the research and helped in facilitating meeting with residents of the village which resulted in unprecedented cooperation among the selected participants.

Informed consent was obtained from participants after having been properly educated about the objective of the study and the confidentiality of data. Questionnaires were used for capturing demographic information (age, sex, educational attainment, occupation and alcohol consumption), prevalence, daily frequency and duration of smokeless tobacco use. Intra-oral examination was conducted to assess for tooth loss and extent, tooth wear lesions, gingival recession, leukoplakia, erythroplakia and abnormal growths. This examination was done using spatula for tissue retraction, mouth mirror for indirect vision, guaze for drying the oral mucosa, caries explorer for caries detection and plaque assessment under adequate illumination using natural light. The oral examination was conducted by 2 dental therapists who were trained and calibrated by the dental surgeon, the prin cipal investigator. The training and calibration were done to facilitate the accurate detection of lesion and achieve concordance among the examiners respectively. The Kappa statistics value for interexaminer reliability in this study was 0.95 .

Tooth loss was reported as present when there exist one or more teeth and absent if teeth are complete in number. In assessment of edentulousness, it was recorded positive if all teeth were missing and negative if the teeth were complete or there was partial edentulism. Assessment of tooth wear constituted evaluating the teeth for any form of wear facets from attrition, abrasion and erosion. The presence of any of these identified tooth wear lesions irrespective of severity was recorded as yes and absence recorded, as no. The presence of gingival recession was reported as apical migration of gingiva below cementoenamel junction with attendant tooth root exposure.

The presence of white and red lesions which cannot be wiped off with gauze were reported as leukoplakia and erythroplakia respectively. The presence of tumour was recorded as abnormal growths because the histological diagnosis was not sought. The data was subjected to descriptive statistics in form of frequencies, cross-tabulation and percentages using Epi-info statistic software version 3.5.2. Test of significance was done using Chi square statistics and $\mathrm{P}<0.05$ was considered as being statistically significant. 


\section{Results}

Out of the 226 participants studied, 119 of them reported smokeless tobacco use giving a prevalence of $52.7 \%$ with majority- 74 (62.2\%) chewing it. More than half-69 (58.0\%) of them have used smokeless tobacco for 6-10years, one tenth-13 (10.9\%) for 15 years and $37(31.1 \%)$ of the participants for more than 10 years. Daily usage frequency among smokeless tobacco using participants are as follows: Once-8 (6.7\%), twice-16 (13.4\%), thrice-3 (2.5\%) and greater than thrice- $92(77.3 \%)$. The smokeless users tobacco user were more of those aged 50-59 years, females, farmers, those with less than post primary education, non alcohol consumers and those that have not received previous dental care than smokeless tobacco users. However, it was only age $(p=0.006)$ and educational attainment $(\mathrm{p}=0.009)$ that were significantly associated with smokeless tobacco use (table 1).

The oral health problems among the participants are gingival recession $(73.4 \%)$, tooth wear lesion $(59.3 \%)$, tooth loss $(31.0 \%)$, dental caries $(23.5 \%)$ leukoplakia (8.4\%), abnormal soft tissue growth $(6.2 \%)$, edentulousness $(4.4 \%)$ and erythroplakia $(0.4 \%)$. Smokeless tobacco users were more likely to have poor oral hygiene, dental caries, gingival recession, leukoplakia, erythroplakia, abnormal growth, tooth wear lesion, experienced tooth loss, and edentulousness than non smokeless tobacco users. However, the significantly associated lesions with smokeless tobacco use were tooth loss $(p=0.008)$, edentulousness $(p=0.016)$, gingival recession $(\mathrm{p}=0.006)$ and leukoplakia $(\mathrm{p}=0.001)$ (table 2).

Table 1: Demographic characteristics of the participants

\begin{tabular}{|c|c|c|c|c|}
\hline \multirow{2}{*}{ Characteristic } & \multicolumn{4}{|c|}{ Smokeless tobacco } \\
\hline & cs Users & Non users & Total & P-value \\
\hline & n (\%) & n $(\%)$ & n $(\%)$ & \\
\hline \multicolumn{4}{|l|}{ Age (years) } & 0.006 \\
\hline $40-49$ & $32(26.9)$ & $48(44.9)$ & $80(35.4)$ & \\
\hline $50-59$ & $59(49.6)$ & $33(30.8)$ & $92(40.7)$ & \\
\hline $60-69$ & $28(23.5)$ & $26(24.3)$ & $54(23.9)$ & \\
\hline \multicolumn{4}{|l|}{ Gender } & 0.327 \\
\hline Male & $35(29.4)$ & $38(35.5)$ & $73(32.3)$ & \\
\hline Female & $84(70.6)$ & $69(64.5)$ & $153(67.7)$ & \\
\hline \multicolumn{4}{|c|}{ Educational attainment } & 0.009 \\
\hline Never in schor & ol $41(34.5)$ & $25(23.4)$ & $66(29.2)$ & \\
\hline Primary & $71(59.7)$ & $63(58.9)$ & $134(59.3)$ & \\
\hline Post primary & $7(5.8)$ & $19(17.7)$ & $26(11.5)$ & \\
\hline \multicolumn{4}{|l|}{ Profession } & 0.303 \\
\hline Farming & $87(73.1)$ & $67(62.6)$ & $154(68.1)$ & \\
\hline Business & $20(16.8)$ & $21(19.6)$ & $41(18.1)$ & \\
\hline Teaching & $7(5.9)$ & $12(11.2)$ & $19(8.4)$ & \\
\hline Others & $5(4.2)$ & $7(6.6)$ & $12(5.4)$ & \\
\hline \multicolumn{5}{|l|}{ Alcohol use } \\
\hline \multicolumn{5}{|l|}{0.569} \\
\hline Yes & 38 (31.9) & $38(35.5)$ & $76(33.6)$ & \\
\hline No & $81(68.1)$ & $69(64.5)$ & $150(66.4)$ & \\
\hline \multicolumn{4}{|c|}{ Previous dental visit } & 0.315 \\
\hline Yes & $38(31.9)$ & $41(38.3)$ & $79(35.0)$ & \\
\hline No & $81(68.1)$ & $66(61.7)$ & $147(65.0)$ & \\
\hline
\end{tabular}


Table 2: Tooth loss and oral health issues among the participants

\begin{tabular}{|c|c|c|c|c|}
\hline \multirow[b]{2}{*}{ Characteristics } & \multicolumn{2}{|c|}{ Smokeless tobacco } & \multirow[b]{2}{*}{$\begin{array}{l}\text { Total } \\
\text { n (\%) }\end{array}$} & \multirow[b]{2}{*}{ P-value } \\
\hline & $\begin{array}{l}\text { Users } \\
\text { n }(\%)\end{array}$ & $\begin{array}{l}\text { Non users } \\
\text { n }(\%)\end{array}$ & & \\
\hline Tooth loss & & & & 0.008 \\
\hline Yes & $46(38.7)$ & $24(22.4)$ & $70(31.0)$ & \\
\hline No & $73(61.3)$ & $83(77.6)$ & $156(69.0)$ & \\
\hline Edentulous & & & & 0.016 \\
\hline Yes & $9(7.6)$ & $1(0.9)$ & $10(4.4)$ & \\
\hline No & $110(92.4)$ & $106(99.4)$ & $216(95.6)$ & \\
\hline Oral hygiene status & & & & 0.494 \\
\hline Good & $12(10.1)$ & $15(14.0)$ & $27(11.9)$ & \\
\hline Fair & $80(67.2)$ & $73(68.2)$ & $153(67.7)$ & \\
\hline Poor & $27(22.7)$ & $19(17.8)$ & $46(20.4)$ & \\
\hline Dental caries & & & & 0.109 \\
\hline Present & $33(27.7)$ & $20(18.7)$ & $53(23.5)$ & \\
\hline Absent & $86(72.3)$ & $87(81.3)$ & $173(76.5)$ & \\
\hline Tooth wear & & & & 0.228 \\
\hline Present & $75(63.0)$ & $59(55.1)$ & $134(59.3)$ & \\
\hline Absent & $44(37.0)$ & $48(44.9)$ & $92(40.7)$ & \\
\hline Gingival recession & & & & 0.006 \\
\hline Present & $73(61.3)$ & $46(43.0)$ & $119(52.7)$ & \\
\hline Absent & $46(38.7)$ & $61(57.0)$ & $107(47.3)$ & \\
\hline \multicolumn{5}{|l|}{ Leukoplakia } \\
\hline Present & $17(14.3)$ & $2(1.9)$ & $19(8.4)$ & 0.001 \\
\hline Absent & $102(85.7)$ & $105(98.1)$ & 207 (91.6) & \\
\hline Erythroplakia & & & & 1.000 \\
\hline Present & $1(0.8)$ & $\mathrm{O}(\mathrm{O} . \mathrm{O})$ & $1(0.4)$ & \\
\hline Absent & $118(99.2)$ & $107(100.0)$ & $225(99.6)$ & \\
\hline Abnormal growth & & & & 0.146 \\
\hline Present & $10(8.4)$ & $4(3.7)$ & $14(6.2)$ & \\
\hline Absent & $109(91.6)$ & $103(96.3)$ & $212(93.8)$ & \\
\hline
\end{tabular}

\section{Discussion}

In this study, the prevalence of smokeless tobacco use was $52.7 \%$ with majority chewing it (62.2\%). This is comparable to findings among adults attending family practice clinics in Karachi, Pakistan (52.4\%)12, hospital staff in Pakistan (48.6\%)13 and sports athletes in United States of America where about half of them in the studies indulge in smokeless tobacco use. ${ }^{14-16}$ However, this is strikingly higher than reported values among adults in African communities. ${ }^{9}$ The rural nature of this community may be the reason for the high prevalence of smokeless tobacco use and showed why more than half of the respondents have been using smokeless tobacco for 6-10 years and greater than thrice daily frequency was reported by more than three-quarters $(77.3 \%)$ of the respondents. Reports have shown higher smokeless tobacco use in rural $\operatorname{areas}^{17-19}$ and mountainous areas. ${ }^{19}$
Tobacco use contributes to higher malnutrition and illiteracy rates, since money that could have been used for food and education is spent on tobacco. ${ }^{5}$ In this study, the smokeless tobacco use was more among those aged 50-59 years. This was statistically significant reflecting smokeless tobacco use as commoner practice among older individuals. Smokeless tobacco was also found to be more common among females than males in this study. This is similar to reports in Bangladesh and Malaysia where use of smokeless tobacco products was found to be more common among females than males. ${ }^{10,20}$ The social and cultural acceptability of this practice among females in developing countries superimposed on their cheap nature may explain the higher smokeless tobacco use among females in this study. The reported more frequent smokeless tobacco use among black African women in comparison with white African women may be 
contributory explanation. ${ }^{21}$ Tobacco use has been reported to be higher among individual with low socioeconomic status and educational attainment. ${ }^{22-}$ ${ }^{24}$ This tallied with the finding of this study where farmers and those with lower educational attainment reported higher prevalence of smokeless tobacco use than their counterparts. This is a pointer to the inextricably link between tobacco use and poverty because of established role of tobacco use in exacerbating poverty and hindering economic development. ${ }^{5}$

In this study, the oral health problems among the participants are gingival recession $(73.4 \%)$, tooth wear lesion (59.3\%), tooth loss (31.0\%), dental caries $(23.5 \%)$ leukoplakia (8.4\%), abnormal soft tissue growth $(6.2 \%)$, edentulousness $(4.4 \%)$ and erythroplakia $(0.4 \%)$. The pattern of oral health problems in middle aged adults and elderly in this community is consistent with findings from other African countries where deficient utilization of dental services is common. ${ }^{25-27}$ The prevalence of these conditions also highlights oral health problems as a serious public health burden in rural areas of developing countries that need urgent and comprehensive attention. Smokeless tobacco user were more likely to have dental caries, gingival recession, leukoplakia, erythroplakia, abnormal growth, tooth loss, edentulousness, tooth wear lesion, and poor oral hygiene than non smokeless tobacco users. Toothache relief cited as the most common reason for initiation of tobacco use may be a possible explanation for the prevalence of oral lesions among smokeless tobacco users. ${ }^{23}$ The poorer hygiene found among the smokeless tobacco users which are linked with dental caries and periodontal disease explains their higher experience of tooth loss and edentulousness in this study. The mechanism through which tobacco cause gingival recession and tooth wear lesion may be through local frictional and vascular effects. The high sugar content, increased gingival recession and enhanced collagenase activity were postulated by Tomar and Winn, (1999) ${ }^{28}$ as reason for increased risk for development of rootsurface caries among chewing smokeless tobacco users.

Studies have implicated the smokeless tobacco use as a risk factor for the development of oral mucosal problems and tumours. ${ }^{29-32}$ The higher prevalence of leukoplakia, erythroplakia and abnormal soft tissue growth among smokeless tobacco user than the non tobacco users in this study

African Health Sciences Vol 13 Issue 3 September 2013 is an added epidemiological evidence of oral effects of smokeless tobacco use.

\section{Conclusion}

Smokeless tobacco use, which was associated with age, educational attainment, tooth loss, gingival recession and leukoplakia experience, was high among adults in Fokoué, Cameroon.

\section{References}

1. Center for Disease Control and Prevention. Tobacco use; targeting the nation's leading killer. http:/ / www.cdc.gov/chronicdisease/ resources/publications/aag/osh.htm\#links

2. Scollo, MM and Winstanley, MH. Tobacco in Australia: Facts and issues. 4th edn. Melbourne: Cancer Council Victoria; 2012. Available from www.TobaccoInAustralia.org.au.

3. Jarvis MJ, Wardle J. Social patterning of health behaviours: the case of cigarette smoking. In: Marmot M, Wilkinson RG, editors. Social determinants of health, 2 edition. Oxford: Oxford University Press; 2006. pp. 224-37.

4. Mackay JL. The fight against tobacco in developing countries. Tuber Lung Dis 1994; 75(1):8-24.

5. World Health Organization. Why tobacco is a public health priority.http://www.who.int/ tobacco/health_priority/en/.

6. Musk AW, de Klerk NH. History of tobacco and health. Respirology 2003; 8(3):286-90.

7. Peltzer K, Phaswana N, Malaka D. Smokeless tobacco use among adults in the Northern Province of South Africa: qualitative data from focus groups. Subst Use Misuse 2001; 36(4):44762.

8. U.S. Department of Health and Human Services. The Health Consequences of Using Smokeless Tobacco: A Report of the Advisory Committee to the Surgeon General. Bethesda, MD: U.S.Department of Health and Human Services, 1986.

9. Desalu OO, Iseh KR, Olokoba AB, Salawu FK, Danburam A. Smokeless tobacco use in adult Nigerian population. Niger J Clin Pract 2010; 13(4):382-7.

10. Flora MS, Mascie-Taylor CG, Rahman M. Gender and locality differences in tobacco prevalence among adult Bangladeshis. Tob Control 2009; 18(6):445-50.

11. Gupta V, Yadav K, Anand K. Patterns of tobacco use across rural, urban, and urban-slum 
populations in a north Indian community. Indian J Community Med 2010; 35(2): 245-251.

12. Ali NS, Khuwaja AK, Ali T, Hameed R. Smokeless tobacco use among adult patients who visited family practice clinics in Karachi, Pakistan. J Oral Pathol Med 2009; 38(5):416-21.

13. Valliani A, Ahmed B, Nanji K, Valliani S, Zulfiqar B, Fakih M, Mehdi M, Khan A, Sheikh SA, Fatima N, Ahmad S, Farah F, Saleem S, Ather S, Majid SK, Hashmi SS, Arjan S. Use of smokeless tobacco amongst the staff of tertiary care hospitals in the largest city of Pakistan. Asian Pac J Cancer Prev 2012; 13(5):2315-7.

14. Sinusas K, Coroso JG, Sopher MD, Crabtree BF. Smokeless tobacco use and oral pathologyin a professional baseball organization. J Fam Pract 1992; 34(6):713-8.

15. Cummings KM, Michalek AM, Carl W, Wood $\mathrm{R}$, Haley NJ. Use of smokeless tobacco in a group of professional baseball players. I Behav Med 1989; 12(6):559-67.

16. Robertson PB, Walsh MM, Greene JC. Oral effects of smokeless tobacco use by professional baseball players. Adv Dent Res 1997; 11(3):30712.

17. Substance Abuse and Mental Health Services Administration (SAMHSA), U.S. Department of Health and Human Services (HHS), Results from the 2010 National Survey on Drug Use and Health: Detailed Tables,http://www.samhsa.gov/data/ N S D U H / 2 k 10 R e s u l t s T a b le s / NSDUHTables2010R/PDF/Cover.pdf

18. Neufeld KJ, Peters DH, Rani M, Bonu S, Brooner RK. Regular use of alcohol and tobacco in India and its association with age, gender, and poverty. Drug Alcohol Depend 2005; 77(3):283-91.

19. Sreeramareddy CT, Ramakrishnareddy N, Harsha Kumar H, Sathian B, Arokiasamy JT. Prevalence, distribution and correlates of tobacco smoking and chewing in Nepal: a secondary data analysis of Nepal Demographic and Health Survey-2006. Subst Abuse Treat Prev Policy 2011 Dec 20; 6:33.

20. Gan CY. Tobacco usage among rural Bajaus in Sabah, Malaysia. Southeast Asian J Trop Med Public Health 1998; 29(3):643-8.

21. Peltzer K. Smokeless tobacco use among urban white and black South Africans. Psychol Rep 1999; 85(3 Pt 1):933-4.

22. Choudhury K, Hanifi SM, Mahmood SS, Bhuiya A. Sociodemographic characteristics of tobacco consumers in a rural area of Bangladesh. $J$ Health Popul Nutr. 2007; 25(4):456-64.

23. Daniel AB, Nagaraj K, Kamath R. Prevalence and determinants of tobacco use in a highly literate rural community in southern India. Natl Med J India 2008; 21(4):163-5.

24. Rooban T, Elizabeth J, Umadevi KR, Ranganathan K. Sociodemographic correlates of male chewable smokeless tobacco users in India: a preliminary report of analysis of National Family Health Survey, 2005-2006. Indian J Cancer 2010; 47Suppl 1:91-100.

25. Arowojolu MO. Gingival recession at the University College Hospital, Ibadan-prevalence and effect of some aetiological factors. Afr J Med Med Sci 2000; 29(3-4):259-63.

26. Ibiyemi O, Taiwo JO. Some socio-demographic attributes as covariates in tooth wear among males in a rural community in Nigeria. Ethiop J Health Sci 2012; 22(3):189-95.

27. Taiwo JO, Onyeaso CO, Kolude BO, Ibiyemi O. Dental caries experience among the elderly population in South East local government area in Ibadan, Nigeria. Odontostomatol Trop 2007; 30(118):31-6.

28. Tomar SL, Winn DM. Chewing tobacco use and dental caries among U.S. men. I Am Dent Assoc 1999; 130(11):1601-10.

29. Guggenheimer J. Implications of smokeless tobacco use in athletes. Dent Clin North Am. 1991; 35(4):797-808.

30. Hoffmann D, Djordjevic MV. Chemical composition and carcinogenicity of smokeless tobacco. Adv Dent Res 1997; 11(3):322-9.

31. Boffetta P, Hecht S, Gray N, Gupta P, Straif K. Smokeless tobacco and cancer. Lancet Oncol 2008; 9(7):667-75.

32. Daniels TE, Hansen LS, Greenspan JS, Grady DG, Hauck WW, Greene JC, Ernster VL. Histopathology of smokeless tobacco lesions in professional baseball players. Associations with different types of tobacco. Oral Surg Oral Med Oral Pathol 1992; 73(6):720-5. 